\title{
Estimating Decline and Distributional Change in Amphibians
}

\author{
DAVID K. SKELLY, ${ }^{*}$ KERRY L. YUREWICZ, $†$ EARL E. WERNER, $†$ \\ AND RICK A. RELYEA
}

*School of Forestry \& Environmental Studies and Department of Ecology \& Evolutionary Biology, Yale University, 370 Prospect Street, New Haven, CT 06511, U.S.A., email david.skelly@yale.edu

†Department of Ecology \& Evolutionary Biology, University of Michigan, Ann Arbor, MI 48109-1048, U.S.A.

‡Department of Biological Sciences, University of Pittsburgh, Pittsburgh, PA 15260, U.S.A.

\begin{abstract}
Concern over species declines has prompted researchers to use bistorical data as a basis for comparison with present-day information from the same sites to assess changes in presence/absence distributions. A review of the literature revealed that these resurveys typically lasted for 1 or 2 years, and many were based on museum records or other data relying on known bistorical presences. Using data on nine amphibian species from a set of 32 ponds at the E. S. George Reserve (ESGR) in Michigan, we evaluated the importance of the duration of a resurvey and the type of historical data used (information on bistorical presences and absences $v$ s. historical presences only). We compared data we collected between 1996 and 2000 with information from the same ponds collected between 1967 and 1974. By systematically degrading the 19962000 data, we determined that a resurvey lasting 1 year would yield an estimated 45\% decline in the number of presences, whereas a resurvey lasting 2 years would yield an estimated $28 \%$ decline. In contrast, a 5-year resurvey would yield an estimated 3\% decline in the number of presences. In addition, when our bistorical data were limited to known presences in the past, even a 5-year resurvey yielded an estimated $30 \%$ decline in the number of presences. Our results suggest that estimates of decline and distributional change can be extremely sensitive to the duration of resurvey effort and the type of historical data used. The pattern we found in analyses of ESGR data is echoed in published studies in which multiple-year resurveys tended to yield smaller estimates of decline than single-year resurveys. Based on our findings, we suggest that future resurveys extend for long enough to estimate the value of additional data and that geographic scales of inference be chosen based on the amount and quality of bistorical information.
\end{abstract}

Estimación de la Declinación y Cambio Distribucional de Anfibios

Resumen: La preocupación por la declinación de especies ha motivado a investigadores a utilizar datos bistóricos como una base para comparar con información actual de los mismos sitios y evaluar así los cambios en distribuciones de presencia/ausencia. Una revisión de literatura reveló que estas re-evaluaciones típicamente duran 1 o 2 años, y muchas se basaron en registros de museos u otros datos de presencia bistórica conocida. Evaluamos la importancia de la duración de una re-evaluación y del tipo de datos bistóricos utilizados (información de presencias y ausencias bistóricas comparado con presencias históricas solamente) utilizando datos de nueve especies de anfibios de un conjunto de 32 charcas en la Reserva E.S. George (RESG) en Michigan. Comparamos los datos recolectados entre 1996 y 2000 con información de las mismas charcas recolectada entre 1967 y 1974. Disgregando sistemáticamente los datos de 1996-2000, determinamos que una re-evaluación de un año produciría una declinación estimada del 45\% en el número de presencias, mientras que una re-evaluación de dos años produjo una declinación estimada del 28\%. En contraste, una re-evaluación de 5 años produjo una declinación estimada del 3\% en el número de presencias. Además, cuando nuestros datos históricos se limitaban a presencias conocidas en el pasado, aún una re-evaluación de 5 años produjo una declinación estimada del 30\% en el número de presencias. Nuestros resultados sugieren que las estimaciones de declinación y de cambios distribucionales pueden ser extremadamente sensibles a la

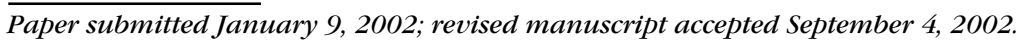

744

Conservation Biology, Pages 744-751

Volume 17, No. 3, June 2003 
duración del esfuerzo de re-evaluación y al tipo de datos bistóricos utilizados. El patrón encontrado en el análisis de datos de RESG se repite en estudios publicados en los que re-evaluaciones de múltiples años tendieron a producir menores estimaciones de declinación en comparación con las re-evaluaciones de un solo año. Con base en nuestros hallazgos, sugerimos que futuras re-evaluaciones se extiendan lo suficiente para estimar el valor de datos adicionales y que se seleccionen las escalas geográficas de inferencia con base en la cantidad y calidad de información bistórica.

\section{Introduction}

Historical data are a critical resource for conservation biologists. Documentation of changes in the distribution and abundance of species is a necessary step in understanding the consequences of past actions and in formulating management strategies. Although long-term monitoring has been identified as the ideal way to collect such information (Caughley \& Gunn 1996), conservation biologists are often forced to deal with species and systems for which long-term data do not exist. In such cases, existing information on known historical presences gleaned from museum records or natural-history databases can offer scientists information about the past distribution of species (Shaffer et al. 1998; Kress et al. 2000; Sugden \& Pennisi 2000; Wilson 2000). These data are more widely available than long-term data sets and thus are commonly used to make inferences regarding changes in the distribution of species.

Concern over the disappearance and decline of amphibians has challenged biologists to estimate distributional changes for species which, in most cases, have not been subject to long-term monitoring programs (Blaustein et al. 1994; Alford \& Richards 1999; Houlahan et al. 2000). In the absence of extensive monitoring data, many amphibian biologists have turned to museum records or other sources of known historical occurrences of species to assess patterns of change leading to present-day distributions (Shaffer et al. 1998). Such resurveys largely show that the focal species are declining (e.g., Fellers \& Drost 1993; Bradford et al. 1994; Lannoo et al. 1994; Fisher \& Shaffer 1996). That is, in comparison with known historical information, the current distribution of presences is reduced.

Resurveys of sites where a species has been recorded are limited to demonstrating that a species distribution has not changed or that the species is undergoing decline (Shaffer et al. 1998; Strayer 1999; Strayer \& Fetterman 1999). These data do not provide information on expansion of the species distribution into new sites because estimates of sampling and collecting effort from sites where the species was not found are typically not available.

Further, for many taxa including amphibians, the number of years needed to adequately characterize the distribution of a species is not obvious. Amphibians can be difficult to detect and may skip breeding in a given year as a result of climate conditions (Heyer et al. 1994). It is not known whether, or to what extent, the use of museum records and similar types of information in combination with shorter-duration resurveys can affect estimates of a decline. We reviewed studies in which historical information was used as a basis for estimating changes in amphibian distributions. We then used information on the distribution of nine amphibian species at the E. S. George Reserve (ESGR) in Michigan (U.S.A.) to estimate the effects of resurvey duration and the type of historical information used on estimates of distributional change.

\section{Methods}

We reviewed the literature to determine the durations of amphibian surveys carried out in sites with historical information on species presence or absence. The review was restricted to studies published since 1990, the year in which reports of global amphibian declines surfaced. We searched for papers by conducting an electronic search of the Web of Science (keyword search criteria: amphib* or anura* or frog* or salamander* or caudat* or urodel* and decline or survey or monitoring or historical). The literature-cited sections of relevant papers uncovered during the initial search were also searched for additional references. Studies were included when authors revisited sites for which historical information on a species was available and for which the duration of the resurvey was clearly described. Resurvey duration was the number of years in which each site was visited. Where the number of years in which sites were revisited varied, we used the modal number. Based on this algorithm, one study (Davidson et al. 2001) was assigned 0-years resurvey duration because the current presence/absence status for more than half of all sites was assigned based on expert opinion rather than field sampling. Studies were also categorized by the type of historical data used: information on presences and absences or presences only.

We analyzed data from published studies uncovered during the literature review by calculating percent decline estimates from resurveys lasting no more than 1 year versus those lasting multiple years. Published stud- 
ies were excluded if they covered only a single site (2 cases) or if it was impossible to calculate percent decline values from information presented in the papers ( 4 cases). Using a $t$ test, we compared angular, transformed decline values from the 14 remaining single and multiyear studies.

To estimate the effects of resurvey duration and the type of resurvey data used on estimates of distributional change, we used data on amphibian presence and absence collected from the 540-ha ESGR in Livingston County, Michigan. Between 1967 and 1974, Collins and Wilbur (1979) visited a set of 32 ponds at the ESGR and noted the presence and absence of amphibian species. Because Collins and Wilbur (1979) did not assay all ponds for salamanders, we restricted our study to the consideration of the nine anuran species reported from the ESGR. Collins and Wilbur (1979) recorded the presence of an anuran species if, during at least 1 year, they found at least one of the following within a pond: sustained chorusing, eggs, larvae, or metamorphs. Data were available only for the entire 1967-1974 block of time; no information on species distribution within individual years survives. Likewise, data on sampling effort expended during the first survey were not available; however, when queried, the authors report they visited most ponds during each of the 8 years of the survey, and in most ponds they made multiple visits each year ( J. P. Collins and H. M. Wilbur, personal communication).

We compared species distributional data from this 1967-1974 dataset with information we collected more recently (between 1996 and 2000). During each of these 5 years we sampled the 32 ponds once during May and once during July. These visits were timed to coincide with the larval development periods of spring and summer breeders, respectively. A sampling visit consisted of both pipe and dipnet sampling. Pipe sampling consisted of dropping a 30-cm-diameter metal pipe through the water column to seal it against the pond bottom. A dipnet was then used to repeatedly sweep the captured volume of water and collect all amphibians (Skelly 1996). The number of pipe samples taken at each sampling visit ranged from 5 to 40 and was correlated with the surface area of the pond. Dipnet sampling was conducted by sweeping a net through representative areas throughout the pond basin to collect amphibians. The total person-minutes of dipnet sampling during a visit to a pond was set equal to the number of pipe samples collected. In addition, in larger ponds with deeper areas, we took two seine hauls with a $7.5-\mathrm{m}$ seine (6-mm mesh).

To estimate the effect of resurvey duration on estimates of distributional change from the 1967-1974 survey, we used subsets of our 1996-2000 data. The presence of an amphibian species in a pond was confirmed by the presence of at least one of the following during the interval of interest: eggs, larvae, or metamorphs. To estimate net change in the distribution of anuran species between the two surveys based on a 5-year resurvey, we used our entire dataset (1996-2000) and tallied the number of ponds in which a formerly absent species was present (denoted as an invasion) and the number of ponds in which a formerly present species was absent between 1996 and 2000 (denoted as an extinction). The change in species distributions was measured as the net change in total number of presences across all nine anuran species. To simulate shorter resurvey durations, we used all possible survey intervals of a given length of time. For example, the results for a 3-year resurvey were found by averaging the net changes based on distributions during 1996-1998, 1997-1999, and 1998-2000. Thus, there were five possible 1-year resurveys, four possible 2-year resurveys, three possible 3-year resurveys, two possible 4-year resurveys, and one 5-year resurvey.

We conducted a second analysis of the ESGR data in which we modified our historical data by restricting it to the record of species presences. This change allowed us to simulate the use of museum records. In this form, for each time interval of interest, we considered only historical presences and calculated the fraction of those ponds for which the species was also present during a designated resurvey period. Thus, if a species was present in each of the locations where it was found historically, its distribution would be recorded as unchanged. Otherwise it would be recorded as declining. Because data in this form include no information about species absences, it is not possible to estimate invasions from them.

\section{Results}

Most commonly, amphibian biologists have resurveyed historical sites during a single year (Fig. 1). Studies lasting more than 2 years are uncommon. In addition, most studies ( 16 of 20 ) have been based on historical data which were, or were comparable to, museum-locality data. That is, the historical data included only known historical presences and no information about historical species absences.

Across the 14 studies providing quantitative estimates of distributional change, most reported declines (the number of presences declined $43 \%$ between surveys on average). When published studies were divided into single- and multiple-year resurveys, single-year resurveys yielded estimated rates of decline more than twice as large as those resurveys lasting multiple years (Fig. 2; $t$ test: $\mathrm{df}=8, t=2.39, p<0.05$ ).

We used our full data set from the ESGR, including estimates of both extinction and invasion, to estimate the effect of resurvey duration (Fig. 3, presence and absence). For all durations, resurveys indicated a decline 


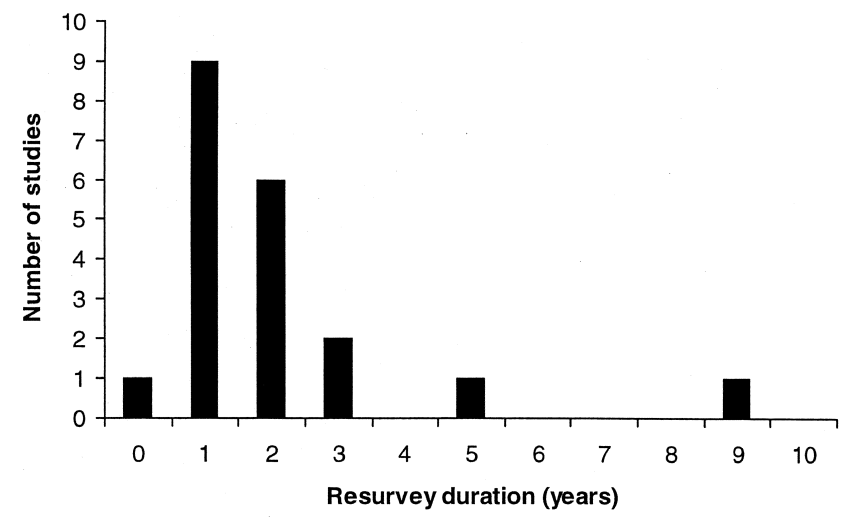

Figure 1. Duration of published resurvey efforts estimating changes in the distribution of amphibians among sites. Each study employed historical data as the basis for revisiting sites. Duration is the modal number of years that each site was resurveyed. Twenty studies are included: Fellers \& Drost (1993), Jung (1993), Bradford et al. (1994), Lannoo et al. (1994), Sjogren Gulve (1994), Busby \& Parmelee (1996), Delis et al. (1996), Fisher \& Shaffer (1996), Gamradt \& Kats (1996), Gillespie \& Hollis (1996), Sullivan et al. (1996), Brandon \& Ballard (1998), Farrar \& Hey (1998), Hay (1998), Tucker (1998), Skelly et al. (1999), Bosch et al. (2001), Corser (2001), and Davidson et al. (2001).

in the number of presences. The estimated size of the decline was strongly affected by the duration of the resurvey, however, which ranged from $45 \%$ of sites lost for a 1 -year resurvey, $28 \%$ for a 2 -year resurvey, $16 \%$ for a 3 -year resurvey, $10 \%$ for a 4 -year resurvey, and only 3\% for a 5-year resurvey.

Resurvey length was important because species often were not present during each year. The probability that a species would be present during a given year (in ponds where it was found at least once between 1996 and 2000) was typically far below 1 (Fig. 4). Pickerel frogs (Rana palustris) had the lowest probability of presence (0.20), and spring peepers (Pseudacris crucifer) had the highest probability of presence (0.79). As a consequence of these probabilities, our accumulation of presence records continued to rise even between the fourth and fifth years of our resurvey (Fig. 5).

By considering only presences from the 1967-1974 survey, we were able to simulate a change in the type of historical data we used (Fig. 3, presence only). In general, restricting our analysis to estimating loss of presences tended to increase estimates of decline relative to a standard based on a net change in the number of presences. The effect of accounting for invasions and extinctions was relatively small, however, when only 1- or 2-year resurveys were considered. Regardless of the type

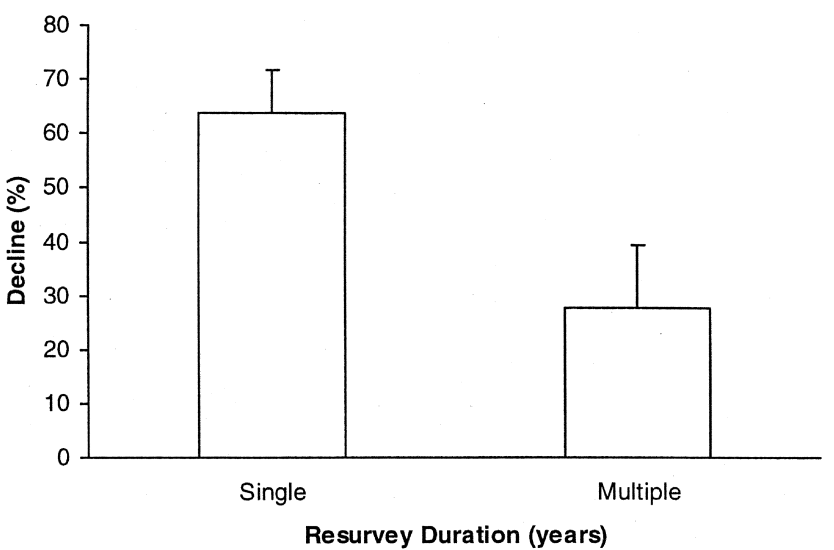

Figure 2. Estimates of percent decline in the number of presences from published resurveys lasting no more than 1 year and those lasting $>1$ year. Eight singleyear studies are included: Fellers \& Drost (1993), Jung (1993), Drost E Fellers (1996), Fisher E Shaffer (1996), Gillespie \& Hollis (1996), Hay (1998), Bosch et al. (2001), and Davidson et al. (2001). Six multiple-year studies are included: Bradford et al. (1994), Lannoo et al. (1994), Sjogren-Gulve (1994), Gamradt E Kats (1996), Skelly et al. (1999), and Corser (2001).

of historical data used, we estimated that the distribution of anuran species had undergone a sizable decline since the first survey period. When longer resurvey periods were considered, however, estimates of decline diverged. When 5 years of resurvey data were considered, historical data considering only presences yielded an estimated $30 \%$ decline in the number of presences,

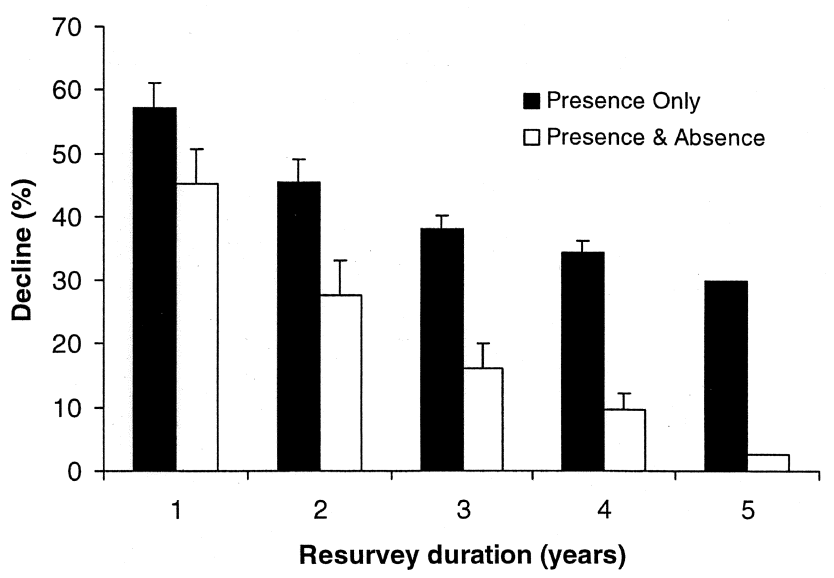

Figure 3. Estimated percent decline in the number of anuran presences during resurveys ranging from 1 to 5 years in duration. Estimates based on bistorical records (1967-1974) of both presence and absence and on bistorical records (1967-1974) of presence only. Bars indicate mean + $1 S E$. 


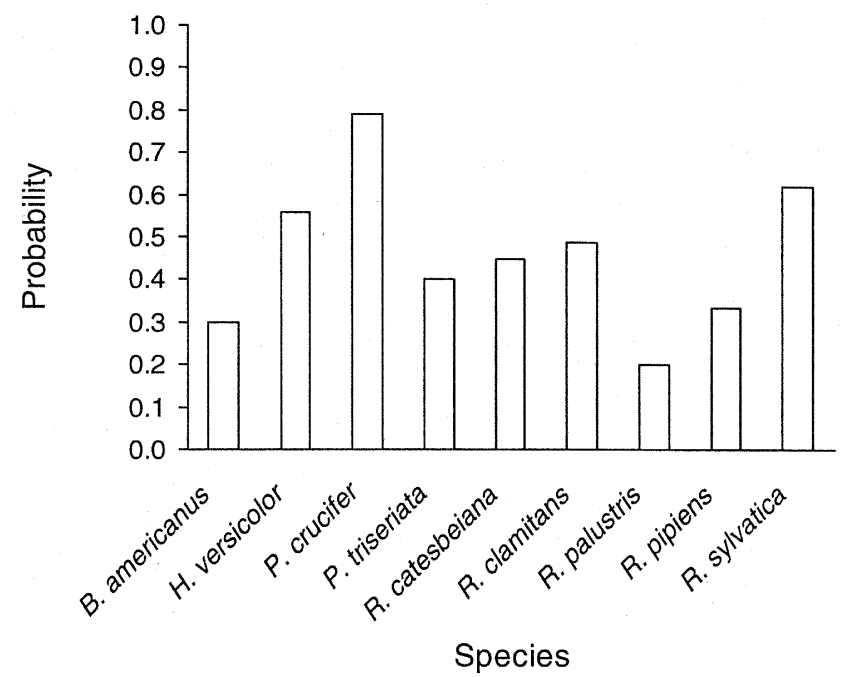

Figure 4. Probability of amphibian species presence within a pond in a single year during our 1996-2000 E. S. George Reserve survey. The probability of presence was calculated for cases in which a species was found in a pond during at least 1 year. This measure ranges from 0.2 if a species was never found in any pond during more than 1 year out of the 5 years sampled to 1.0 if a species was present during each of 5 years in any pond where it was ever found.

whereas estimates based on historical presence and absence information yielded an estimated 3\% decline in the number of presences.

\section{Discussion}

Researchers estimating distributional changes of amphibians have concluded that species are declining (e.g., Hay 1998; Bosch et al. 2001). In general, resurveys have been based on historical records of past presences and have lasted for short periods (1-2 years). Our analyses of data collected from the ESGR showed that both resurvey duration and the type of historical information used can greatly influence estimates of distributional change and decline. If we had ceased our resurvey after 1 or 2 years, or if we had not had information on historical absences, we might have concluded that amphibian populations are undergoing steep decline. In fact, we have shown that the amphibians at the ESGR have been undergoing substantial changes in their distributions, but there is little indication that species are declining (Skelly et al. 1999; E.E.W. et al., unpublished data). Our results suggest that estimates from previous studies may have been affected by the duration of resurvey or by the type of historical data used. If true, understanding the influ-

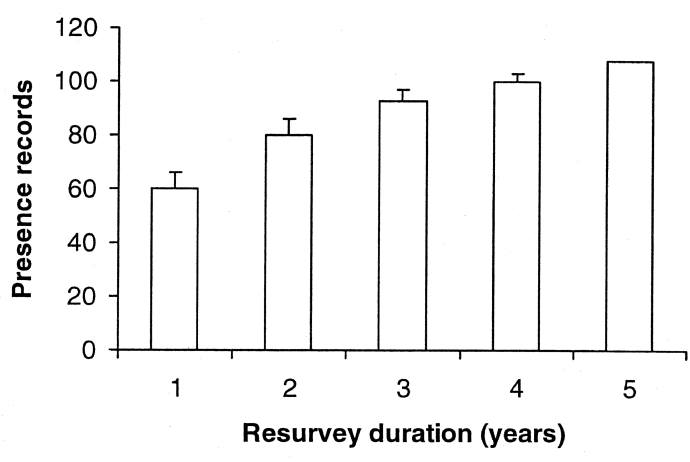

Figure 5. Number of presence records detected during surveys of 32 ponds at the E. S. George Reserve, 19962000. Each bar represents the average number of presences detected during all possible combinations of 1,2, 3, 4, or 5 years of sampling between 1996 and 2000.

ence of these factors will be critical to interpretation of past and future resurvey findings.

Why does resurvey duration have such a large impact? Our study and others (Hecnar \& M'Closkey 1996; Carlson \& Edenhamn 2000; Corser 2001) indicate that amphibian presence/absence distributions change from year to year. There are two types of explanations for this pattern. Year-to-year changes in distribution could result from inadequate sampling effort. Perhaps a species is present each year but is detected only sporadically. We believe that this explanation is not a major factor in our findings. Our sampling was intensive; each pond was visited twice each year, and each visit lasted up to 9 person-hours of sampling effort. Our sampling protocol involved up to three different collection methods and is able to detect species even at extremely low densities (E.E.W. et al., unpublished data). In addition, presence records during our resurvey typically resulted from multiple captures of a species within a given pond; presences resulting from captures of a single individual can indicate low power of detection (Strayer 1999). Finally, we collected frog-chorusing information from many of the survey ponds over the same time period (E.E.W. et al., unpublished data). These records showed strong correspondence between calling activity and species during larval sampling.

Instead of inadequate sampling effort, we believe that changes in distribution between years reflect amphibian behavior. Amphibians are known to forego breeding during years in which the climate is unfavorable (Pechmann et al. 1991). We noted sharp drops in the number of presences during 1999 and 2000, when southeastern Michigan was undergoing a severe drought (Southeastern Michigan Council of Governments, available from http://climate.geo.msu.edu/semcog/sem/mainsem.html), but witnessed quick rebounds during 2001 after ponds refilled (E.E.W. et al., unpublished data). Consequently, 
a 1- or 2-year resurvey during the 1999-2000 interval would have indicated much larger declines than resurveys of equal length from the remainder of the 19962000 period.

Some amphibian species are known to have breeding congregations that move from year to year (Marsh et al. 1999). This phenomenon was noted by Collins (1975) in a mark-and-recapture study of the American toad (Bufo americanus) at the ESGR. In our study, B. americanus had one of the lowest probabilities of presence of any of our study species (Fig. 4). Although we used ponds as sampling sites (following the protocol of the 1967-1974 survey), it may be that populations of B. americanus and other species use more than one breeding pond. Such movements could increase pond-based estimates of invasion and extinction. For biological as well as statistical reasons, distributions of such species may be more reliably analyzed at coarser spatial scales (e.g., Fisher \& Shaffer 1996).

Museum records and natural-history databases often hold the only historical information for the distribution of a species. When used as the basis for a resurvey, however, museum records can lead to much larger estimates of decline than surveys based on both presence and absence information (Strayer \& Fetterman 1999; this study). By converting historical records at the ESGR to presence information only, we estimated declines of up to $50 \%$. Even when our resurvey lasted 5 years, we still would have estimated that a large fraction (approximately onethird) of species with historical presences had gone extinct. Estimates of distributional change based on museum records can remain high even in the face of substantially increased resurvey duration. For our data, this pattern stemmed from persistent absences from historical locations for several species. It appears that many of these persistent absences are linked to land-cover changes. As the ESGR undergoes forest succession, many species have disappeared from pond basins that have been enveloped by tree canopies (Skelly et al. 1999; Werner \& Glennemeier 1999; Skelly et al. 2002). A resurvey based on historic presences accurately reflects these losses but is incapable of accounting for the numerous invasions that have occurred during the same period. For species living in changing landscapes, such dynamics may be common (Sjogren-Gulve 1994; Skelly et al. 1999; Skelly 2001). Where shifting landscape mosaics exist, resurveys based on museum records may be particularly vulnerable to misinterpretation.

Given the limitations of much of our historical data and the important purposes to which they are applied, what is the relevance of our results for future resurveys? Those planning a resurvey are confronted with an array of issues over which they have little control (e.g., the form of existing historical data, whether information on past sampling effort is available), but researchers can often determine the duration of a resurvey. Our results suggest that increases above 1 or 2 years may yield improved estimates of distributional change (Fig. 3). Determination of the adequate duration of a resurvey depends on the biology of the species being surveyed and the amount of effort that can be expended at each site. All surveys that extend for multiple years, however, will produce information on the regularity of presence detection for each species being studied (Fig. 4). The resulting rate at which new presences are accumulated in succeeding years (Fig. 5) can provide information on the degree to which additional sampling effort would alter estimates of distributional change (Gotelli \& Colwell 2001).

In addition, resurveyors can also control their geographic unit of inference (Shaffer et al. 1998). Some problems of interpretation we uncovered can be alleviated by considering whether the quality of historical data justifies attempts to determine the status of historic and current species in specific locations. Particularly when resurveys are based on limited past information, researchers can trade off the level of detail of their analysis for the robustness of their conclusions by focusing on coarser levels of distribution within entire counties, national parks, or other geographic units for which a number of historical records are known (e.g., Fisher \& Shaffer 1996). In our study, the number of species recorded across the ESGR was constant between 1996 and 2000 in spite of large fluctuations in the number of presences recorded from year to year $(\mathrm{CV}=21 \%)$. At this level of inference, conclusions were independent of resurvey duration and the type of historical data used.

There is abundant evidence that a number of amphibian species and other taxa are no longer present within large parts of their historic ranges or have disappeared entirely (Sauer et al. 1996; Allen-Wardell et al. 1998; Alford \& Richards 1999). As the issue of whether declines have occurred has receded, a premium has begun to be placed on information related to the prevalence, degree, and causes of distributional changes (Pounds et al. 1997; Skelly \& Meir 1997; Semlitsch 2000; Davidson et al. 2001; Marsh \& Trenham 2001; Young et al. 2001). Resurveys will be critical to our efforts to understand where and why distributions change and species decline. Our findings strongly imply that both the pattern and degree of previously published estimates of decline may have been influenced by the duration of resurvey efforts and the type of historical data used. To increase their utility, future resurvey studies would benefit from efforts to gauge the sensitivity of estimates of decline and distributional change.

The utility to conservation biologists of historical data, and of museum records in particular, has been widely declared (e.g., Kress et al. 2000; Sugden \& Pennisi 2000; Wilson 2000). These data are undoubtedly of critical value and often represent the only historical ecological information on a species. Less attention has been paid, 
however, to the strategies required to apply such information to species conservation (for an exception, see Strayer 1999). To meet the diverse challenges they face, conservation biologists need to use historical information from all available sources with the greatest possible efficiency and effectiveness. Toward this end, future resurveys will benefit from a strategic perspective that begins with a consideration of the historical data. Most resurveyors will not have access to information on historical absences. Although the structure of any resurvey will be guided by the goals of the project that spawned it, the effect of relying solely on presence information should not be ignored. In many cases it may be necessary to adjust expectations about what resurveys are capable of telling us. The best resurveys will provide information on the degree to which conclusions would be altered by increasing the duration of the resurvey or by changing the scale of the geographic unit under consideration.

\section{Acknowledgments}

We thank C. Davis for outstanding assistance during the recent E. S. George Reserve Survey and the many people who helped sample ponds. This paper has benefited from the comments of A. Blaustein, C. Davidson, C. Davis, K. Freidenburg, S. McCauley, L. Schiesari, M. Zimmerman, and an anonymous reviewer. Our research has been supported by the National Science Foundation Long Term Research in Environmental Biology Program (DEB-9727014) and by the National Institutes of Health and the National Science Foundation (5R01ES011067-02).

\section{Literature Cited}

Alford, R. A., and S. J. Richards. 1999. Global amphibian declines: a problem in applied ecology. Annual Review of Ecology and Systematics 30:133-165.

Allen-Wardell, G., et al. 1998. The potential consequences of pollinator declines on the conservation of biodiversity and stability of food crop yields. Conservation Biology 12:8-17.

Blaustein, A. R., D. B. Wake, and W. P. Sousa. 1994. Amphibian declines: judging stability, persistence, and susceptibility of populations to local and global extinctions. Conservation Biology 8: 60-71.

Bosch, J., I. Martinez-Solano, and M. Garcia-Paris. 2001. Evidence of a chytrid fungus infection involved in the decline of the common midwife toad (Alytes obstetricans) in protected areas of central Spain. Biological Conservation 97:331-337.

Bradford, D. F., D. M. Graber, and F. Tabatabai. 1994. Population declines of the native frog, Rana muscosa, in Sequoia and Kings-Canyon National Parks, California. Southwestern Naturalist 39:323-327.

Brandon, R. A., and S. R. Ballard. 1998. Status of Illinois chorus frogs in southern Illinois. Pages 102-114 in M. J. Lannoo, editor. Status and conservation of midwestern amphibians. University of Iowa Press, Iowa City.

Busby, W. H., and J. R. Parmelee. 1996. Historical changes in a herpetofaunal assemblage in the Flint Hills of Kansas. American Midland Naturalist 135:81-91.
Carlson, A., and P. Edenhamn. 2000. Extinction dynamics and the regional persistence of a tree frog metapopulation. Proceedings of the Royal Society of London Series B 267:1311-1313.

Caughley, G., and A. Gunn. 1996. Conservation biology in theory and practice. Blackwell Science, Cambridge, Massachusetts.

Collins, J. P. 1975. A comparative study of the life history strategies in a community of frogs. Ph.D. dissertation. University of Michigan, Ann Arbor.

Collins, J. P., and H. M. Wilbur. 1979. Breeding habits and habitats of the amphibians of the E. S. George Reserve, Michigan, with notes on the distribution of fishes. Occasional paper 686. Museum of Zoology, University of Michigan, Ann Arbor.

Corser, J. D. 2001. Decline of disjunct green salamander (Aneides aeneus) populations in the southern Appalachians. Biological Conservation 97:119-120.

Davidson, C., H. B. Shaffer, and M. R. Jennings. 2001. Declines of the red-legged frog: climate, UV-B, habitat, and pesticides hypotheses. Ecological Applications 11:464-479.

Delis, P. R., H. R. Mushinsky, and E. D. McCoy. 1996. Decline of some west-central Florida anuran populations in response to habitat degradation. Biodiversity and Conservation 5:1579-1595.

Drost, C. A., and G. M. Fellers. 1996. Collapse of a regional frog fauna $n$ the Yosemite area of the California Sierra Nevada, USA. Conservation Biology 10:414-425.

Farrar, E. S., and J. D. Hey. 1998. Status of the plains spadefoot toad in western Iowa. Pages 72-78 in M. J. Lannoo, editor. Status and conservation of midwestern amphibians. University of Iowa Press, Iowa City

Fellers, G. M., and C. A. Drost. 1993. Disappearance of the cascades frog Rana cascadae at the southern end of its range, California, USA. Biological Conservation 65:177-181.

Fisher, R. N., and H. B. Shaffer. 1996. The decline of amphibians in California's great central valley. Conservation Biology 10:1387-1397.

Gamradt, S. C., and L. B. Kats. 1996. Effect of introduced crayfish and mosquito fish on California newts. Conservation Biology 10:1155-1162.

Gillespie, G. R., and G. J. Hollis. 1996. Distribution and habitat of the spotted tree frog, Litoria spenceri DuBois (Anura:Hylidae), and an assessment of potential causes of population declines. Wildlife Research 23:49-75.

Gotelli, N. J., and R. K. Colwell. 2001. Quantifying biodiversity: procedures and pitfalls in the measurement and comparison of species richness. Ecology Letters 4:379-391.

Hay, R. 1998. Blanchard's cricket frogs in Wisconsin: a status report. Pages $79-82$ in M. J. Lannoo, editor. Status and conservation of midwestern amphibians. University of Iowa Press, Iowa City.

Hecnar, S. J., and R. T. M'Closkey. 1996. Regional dynamics and the status of amphibians. Ecology 77:2091-2097.

Heyer, W. R., M. A. Donnelly, R. W. McDiarmid, L. C. Hayek, and M. S. Foster. 1994. Measuring and monitoring biological diversity: standard methods for amphibians. Smithsonian Institution Press, Washington, D.C.

Houlahan, J. E., C. S. Findlay, B. R. Schmidt, A. H. Meyer, and S. R. Kuzmin. 2000. Quantitative evidence for global amphibian declines. Nature 404:752-755.

Jung, R. E. 1993. Blanchard's cricket frogs (Acris crepitans blanchardi) in southwest Wisconsin. Transactions of the Wisconsin Academy of Science, Arts \& Letters 1:79-87.

Kress, W. J., S. E. Miller, G. A. Krupnick, and T. E. Lovejoy. 2000. Museum collections and conservation efforts. Science 291:828-829.

Lannoo, M. J., K. Lang, T. Waltz, and G. S. Phillips. 1994. An altered amphibian assemblage: Dickinson County, Iowa, 70 years after Frank Blanchard's survey. American Midland Naturalist 131: 311-319.

Marsh, D. M., and P. C. Trenham. 2001. Metapopulation dynamics and amphibian conservation. Conservation Biology 15:40-49.

Marsh, D. M., E. H. Fegraus, and S. Harrison. 1999. Effects of breeding pond isolation on the spatial and temporal dynamics of pond use 
by the tungara frog, Physalaemus pustulosus. Journal of Animal Ecology 68:804-814.

Pechmann, J. H. K., et al. 1991. Declining amphibian populations: the problem of separating human impacts from natural fluctuations. Science 253:892-895.

Pounds, J. A., M. P. L. Fogden, J. M. Savage, and G. C. Gorman. 1997. Tests of null models for amphibian declines on a tropical mountain. Conservation Biology 11:1307-1322.

Sauer, J. R., G. W. Pendleton, and B. G. Peterjohn. 1996. Evaluating causes of population change in North American insectivorous songbirds. Conservation Biology 10:465-478.

Semlitsch, R. D. 2000. Principles for management of aquatic-breeding amphibians. Journal of Wildlife Management 64:615-631.

Shaffer, H. B., R. N. Fisher, and C. Davidson. 1998. The role of natural history collections in documenting species declines. Trends in Ecology \& Evolution 13:27-30.

Sjogren Gulve, P. 1994. Distribution and extinction patterns within a northern metapopulation of the pool frog, Rana lessonae. Ecology 75:1357-1367.

Skelly, D. K. 1996. Pond drying, predators, and the distribution of Pseudacris tadpoles. Copeia 996:599-605.

Skelly, D. K. 2001. Distributions of pond-breeding anurans: an overview of mechanisms. Israel Journal of Zoology 47:313-332.

Skelly, D. K., and E. Meir. 1997. Rule-based models for evaluating mechanisms of distributional change. Conservation Biology 11: 531-538.
Skelly, D. K., E. E. Werner, and S. A. Cortwright. 1999. Long-term distributional dynamics of a Michigan amphibian assemblage. Ecology 80:2326-2337.

Skelly, D. K., L. K. Freidenburg, and J. M. Kiesecker. 2002. Forest canopy and the performance of larval amphibians. Ecology 83:983-992.

Strayer, D. L. 1999. Statistical power of presence-absence data to detect population declines. Conservation Biology 13:1034-1038.

Strayer, D. L., and A. R. Fetterman. 1999. Changes in distribution of freshwater mussels (Unionidae) in the upper Susquehanna River basin. American Midland Naturalist 142:328-339.

Sugden, A., and E. Pennisi. 2000. Diversity digitized. Science 289:2305.

Sullivan, B. K., R. W. Bowker, K. B. Malmos, and E. W. A. Gergus. 1996. Arizona distribution of three Sonoran desert anurans: Bufo retiformis, Gastrophryne olivacea, and Pternobyla fodiens. Great Basin Naturalist 56:38-47.

Tucker, J. K. 1998. Status of Illinois chorus frogs in Madison County, Illinois. Pages 94-101 in M. J. Lannoo, editor. Status and conservation of midwestern amphibians. University of Iowa Press, Iowa City.

Werner, E. E., and K. S. Glennemeier. 1999. Influence of forest canopy on the breeding pond distributions of several amphibian species. Copeia 999:1-12.

Wilson, E. O. 2000. Museum collections and conservation efforts. Science 289:2279.

Young, B. E., et al. 2001. Population declines and priorities for amphibian conservation in Latin America. Conservation Biology 15: $1213-1223$

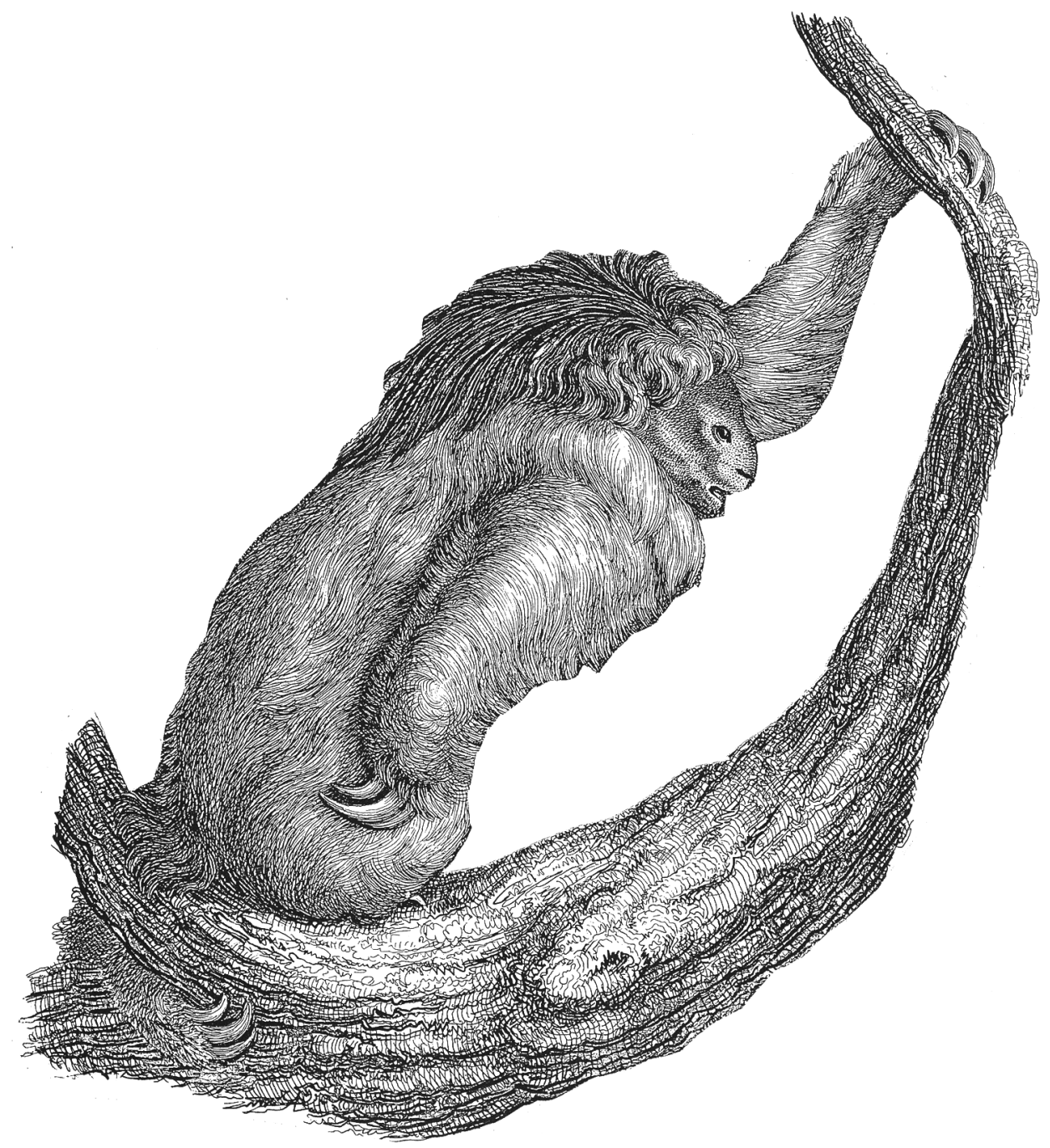

